\title{
Efficacy and safety of once-yearly zoledronic acid in Japanese patients with primary osteoporosis: two-year results from a randomized placebo-controlled double-blind study (ZOledroNate treatment in Efficacy to osteoporosis; ZONE study)
}

\author{
T. Nakamura ${ }^{1}$ - M. Fukunaga ${ }^{2}$ - T. Nakano ${ }^{3}$ - H. Kishimoto ${ }^{4}$ - M. Ito $^{5}$ • H. Hagino ${ }^{6}$ $^{-}$

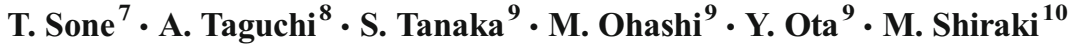

Received: 7 June 2016 / Accepted: 8 August 2016 /Published online: 8 September 2016

(C) The Author(s) 2016. This article is published with open access at Springerlink.com

\begin{abstract}
Summary In a 2-year randomized, placebo-controlled study of 665 Japanese patients with primary osteoporosis, onceyearly administration of zoledronic acid $(5 \mathrm{mg})$ reduced the risk of new morphometric vertebral fractures.

Introduction The purpose of this study was to determine the efficacy and safety of once-yearly intravenous infusion of ZOL in Japanese patients with primary osteoporosis.

Methods This was a two-year multicenter, randomized, placebo-controlled, double-blind, parallel-group comparative study (ZONE Study). Subjects were 665 Japanese patients between the ages of 65 and 89 years who had prevalent vertebral fracture. Subjects were randomly assigned to receive once-yearly intravenous infusion of $5 \mathrm{mg}$ of ZOL or placebo at baseline and 12 months.

Results The 2-year incidence of new morphometric vertebral fracture was $3.0 \%$ (10/330 subjects) in the ZOL group and $8.9 \%(29 / 327)$ in the placebo group $(p=0.0016)$. The $24-$ month cumulative incidence of new morphometric vertebral
\end{abstract}

T. Nakamura

t-nak@utopia.ocn.ne.jp

Japan Osteoporosis Foundation, 11-2 Kobuna-cho, Nihonbashi, Chuo-ku, Tokyo 103-0024, Japan

2 Kawasaki Medical School, 577 Matsushima, Kurashiki City, Okayama 701-0192, Japan

3 Tamana Central Hospital, 1950 Naka, Tamana City, Kumamoto 865-0064, Japan

4 Nojima Hospital, 2714-1 Sesakimachi, Kurayoshi City, Tottori 682-0863, Japan

5 Nagasaki University, 1-14 Bunkyomachi, Nagasaki City, Nagasaki 852-8521, Japan fracture was $3.3 \%$ in the ZOL group versus $9.7 \%$ in the placebo group (log-rank test: $p=0.0029$; hazard ratio: 0.35 ; $95 \%$ confidence interval: $0.17-0.72$ ). The cumulative incidence of any clinical fracture, clinical vertebral fracture, and non-vertebral fracture was significantly reduced in the ZOL group by 54,70 , and $45 \%$, respectively, compared to the placebo group. At 24 months, ZOL administration increased bone mineral density in the lumbar spine, femoral neck, and total hip ( $t$ test: $p<0.0001$ ). No new adverse events or osteonecrosis of the jaw were observed in this study. Conclusions Once-yearly administration of ZOL $5 \mathrm{mg}$ to Japanese patients with primary osteoporosis reduced the risk of new morphometric vertebral fractures and was found to be safe.

Keywords Antiresorptives · Biochemical markers of bone turnover $\cdot$ Clinical trials $\cdot$ Fracture prevention $\cdot$ Osteoporosis

6 School of Health Science, Tottori University, 86 Nishicho, Yonago City, Tottori 683-8503, Japan

7 Department of Nuclear Medicine, Kawasaki Medical School, 577 Matsushima, Kurashiki City, Okayama 701-0192, Japan

8 Department of Oral and Maxillofacial Radiology, Matsumoto Dental University, 1780 Hirooka Gobara, Shiojiri City, Nagano 399-0781, Japan

9 Asahi Kasei Pharma Corporation, 1-105 Jinbocho, Kanda, Chiyoda-ku, Tokyo 101-8101, Japan

10 Research Institute and Practice for Involutional Diseases, 1610-1 Meisei, Misato, Azumino, Nagano 399-8101, Japan 


\section{Introduction}

Zoledronic acid (ZOL) is a bisphosphonate that contains an imidazole ring in a side chain, which, with once-yearly intravenous infusion, has been shown to cause an increase in bone mineral density (BMD) that is mediated by a potent inhibitory effect on bone resorption [1]. ZOL has already been approved in a number of countries for postmenopausal osteoporosis [2-5], glucocorticoid-induced osteoporosis [6], and male osteoporosis [7], and for each indication, the dosage and administration are identical ("once-yearly intravenous infusion of $5 \mathrm{mg}$ of ZOL").

In one large-scale clinical study, the Health Outcomes and Reduced Incidence with Zoledronic acid Once Yearly-Pivotal Fracture Trial (HORIZON-PFT), 7736 patients with postmenopausal osteoporosis received once-yearly intravenous infusion of ZOL at a dose of $5 \mathrm{mg}$. After 3 years of treatment, a significant risk reduction of vertebral fractures was observed [5]. ZOL has also been shown to reduce the risk of hip and non-vertebral fractures due to osteoporosis and to increase BMD in the total hip, femoral neck, lumbar spine, and distal radius $[5,8]$.

The efficacy of once-yearly intravenous infusion, however, has not been examined in Japanese patients with primary osteoporosis. We conducted a 2-year placebo-controlled, randomized, double-blind comparative study to determine the fracture prevention and safety in Japanese patients with primary osteoporosis (ZOledroNate treatment in Efficacy to osteoporosis; ZONE study). We hypothesized that once-yearly intravenous infusion of ZOL is effective and safe in Japanese patients with primary osteoporosis.

\section{Materials and methods}

\section{Study design and treatment}

This was a multicenter, randomized, placebo-controlled, double-blind, parallel-group, comparative study conducted in Japan. All subjects were randomly assigned to either ZOL $5 \mathrm{mg}$ or placebo group in a 1:1 ratio by dynamic allocation based on the minimization method using sex and maximum grade of prevalent vertebral fractures at enrollment as randomization factors. Randomized subjects were administered the study drug once yearly by intravenous infusion (over $15 \mathrm{~min}$ ), and after administration, efficacy and safety issues were evaluated.

The duration of the study was 2 years. All subjects received daily oral supplements of 610-mg calcium, 400-IU vitamin D, and 30-mg magnesium. When acute-phase reactions (APRs) occurred due to the administration of the study drug, investigators were allowed to give the patients ibuprofen as a rescue drug. The start of administration of study drug was postponed if body temperature was $\geq 37.0^{\circ} \mathrm{C}$ until it came down below $37.0{ }^{\circ} \mathrm{C}$.

\section{Study subjects}

Subjects were ambulatory patients who had been diagnosed with primary osteoporosis based on the Diagnostic Criteria for Primary Osteoporosis of the Japanese Society for Bone and Mineral Research (JSBMR) [9]; patients who have fragility fractures caused by low BMD (young adult mean $<80 \%$; score $<-1.7$ ), with between one and four vertebral fractures from the fourth thoracic to the fourth lumbar vertebra (Th4 to L4). Subjects were male and female Japanese patients aged between 65 and 89 years at the time of providing informed consent.

Key exclusion criteria were a history of bisphosphonate use within 2 years prior to the study; serious complications including the heart, liver, or kidney disease; creatinine clearance $<35.0 \mathrm{~mL} / \mathrm{min}$ or urinary protein $\geq 2+$; serum calcium $<8.0 \mathrm{mg} / \mathrm{dL}$ or $>11.0 \mathrm{mg} / \mathrm{dL}$; and undergoing or planning to undergo an invasive dental procedure of the jaw bone, such as tooth extraction, at the time informed consent was obtained.

This study was conducted in compliance with the World Medical Association Declaration of Helsinki-Ethical Principles for Medical Research Involving Human Subjects and Good Clinical Practice. The protocol was reviewed by the institutional review board at each study site. Written informed consent was obtained from all subjects before enrollment in the study.

\section{Efficacy endpoints}

Primary endpoint was the incidence of new morphometric vertebral fracture. Secondary endpoints were the incidence of clinical fracture (any clinical fractures, clinical vertebral fractures, and non-vertebral fractures), changes from baseline in the BMD of the lumbar spine, femoral neck, total hip, and changes in the bone turnover markers. The incidence of osteoporotic fracture was also evaluated. Osteoporotic fractures were defined as the fractures identified by radiographs at the spine, distal forearm, humerus, ribs, clavicle/scapula/sternum, pelvis, tibia/fibula, hip, and other femoral fractures (classified by the World Health Organization [WHO] Scientific Group) [10].

\section{Efficacy measures}

To assess efficacy for vertebral fractures, radiographs of the thoracic and lumbar vertebrae were taken at baseline and at 6 , 12, 18, and 24 months. An independent committee of three experts who were blinded to treatment (TN, HK, MI) compared radiographs and evaluated them based on semiquantitative (SQ) methodology as well as using a quantitative method 
(QM) based on measurements of vertebral height [9]. The incidence of vertebral fracture was defined based on methods described by Genant et al. [11] and Wu et al. [12] as follows: "Comparison of vertebral body before and after administration reveals a change in grade, and there is a decrease of $\geq 20 \%$ in either the anterior, central, or posterior vertebral height of each vertebral body." Clinical fracture was defined as a fracture confirmed on radiographs with clinically evident symptoms such as pain on the back of the trunk or in the extremities. Clinical fractures were initially identified by physicians at each site and confirmed by radiographs or MRI.

The lumbar spine, femoral neck, and total hip BMD were measured using dual-energy X-ray absorptiometry (DXA) at baseline and at 6,12, and 24 months. These were measured at 49 study sites capable of performing DXA measurements. All study sites used the same DXA brand (Hologic Co., Bedford, MA). Acceptance or rejection of the data and the need for reanalysis were determined by the BMD Committee (MF, $\mathrm{HH}$, TS). Serum bone turnover markers were measured at baseline and at 1, 2, 4, and 12 weeks and 6,12, 18, and 24 months after the first infusion and at 1,2, and 4 weeks after the second infusion. All samples were collected under fasted conditions. Serum was frozen, while urine was stored refrigerated until measurement. All samples were analyzed at a central laboratory (LSI Medience Corporation, Tokyo, Japan). To maintain blinding, the results of the bone turnover marker analysis were stored centrally until the database was locked and the study was unblinded. The bone resorption markers measured were type I collagen cross-linked Ctelopeptide (CTx) (Elecsys $\beta$-CrossLaps/serum; with interassay coefficients of variation of $1.8-6.0 \%$ ) and bone alkaline phosphatase (BAP) (Access Ostase; 2.3-3.7\%).

\section{Adverse events}

Subjects were assessed for AEs either through self-reporting, medical interviews, or other tests. Recorded items were the $\mathrm{AE}$ name, date of onset, intervention, outcome, seriousness, severity, and relationship with the study drug. Investigators interviewed subjects every 3 months with a focus on AEs in the oral cavity and whether the subject was undergoing any dental treatment. Subjects were requested to measure their body temperature four times a day if they felt feverish after infusion and detail it in their self-report form. Twelve-lead electrocardiogram tests were measured at baseline and at $1 \mathrm{~h}, 1$ week, and 2 weeks after the first infusion at study sites capable of performing measurements for QT/QTc elongation.

\section{Statistical analyses}

This study was designed to have $90 \%$ power to detect a $50 \%$ reduction in the risk of new morphometric vertebral fracture in the ZOL group, assuming an incidence of 19 to $21 \%$ in the placebo group at 24 months based on data from previous clinical trials $[13,14]$ and a $10 \%$ subject discontinuation rate. It was determined that at least 298 subjects per group were required. All efficacy analyses were conducted on the full analysis set (FAS). The FAS included all randomized subjects except for those who did not have osteoporosis, did not receive the infusion, and had no available efficacy data after the first dose of the study drug. The safety analysis set consisted of subjects who received at least one infusion.

For the primary analysis of efficacy, the incidence of new morphometric vertebral fracture over 24 months was analyzed based on the Kaplan-Meier method and using log-rank tests (two-tailed significance level of $5 \%$ ). New morphometric vertebral fractures were identified by comparing radiographs taken at baseline and at each follow-up visit. The incidence of new morphometric vertebral facture was also presented as a hazard ratio (HR), and the $95 \%$ confidence interval (CI) was calculated by Cox regression analysis. The relative risk (RR) was also calculated. Between-group analysis in the incidence of new morphometric vertebral facture was assessed by Fisher's exact test. Clinical fractures were assessed by the Kaplan-Meier method. The incidence of osteoporotic fracture was assessed by Fisher's exact test. Change from baseline in BMD and bone turnover markers was compared using the $t$ test.

For AE data, the number and percentage of subjects were calculated based on the presence or absence of AEs in each treatment group. Between-group analysis was performed by Fisher's exact test for the incidence of AEs and drug-related AEs. The two-tailed significance level was set at 5 and $95 \%$ CIs that were calculated. AE occurrences were summarized and encoded using the Medical Dictionary for Regulatory Activities Terminology (MedDRA, MedDRA/J Version 17.1).

\section{Results}

\section{Subjects}

A total of 1311 subjects were screened at 73 study sites in Japan (Fig. 1). Of these, 665 subjects were randomized into two arms to receive either ZOL $(n=333)$ or placebo $(n=332)$. Among these subjects, 542 completed the study (ZOL arm: $n=258$; placebo arm: $n=284$ ). Analyses were performed on 661 subjects including 330 subjects (female: 309 , male: 21 ) in the ZOL arm and 331 subjects (female: 312, male: 19) in the placebo arm based on the FAS (Table 1). No differences were observed between the two arms in any of the baseline characteristics in either randomized or completed population.

\section{Fracture}

The 2-year incidence of new morphometric vertebral fracture was $3.0 \%$ (10/330 subjects) in the ZOL group and $8.9 \%$ (29/ 


\begin{tabular}{|c|c|}
\hline \multicolumn{2}{|l|}{$\begin{array}{l}\text { Screened } \\
\mathrm{N}=1311\end{array}$} \\
\hline & \\
\hline $\begin{array}{l}\text { Randomized (Administered) } \\
\mathrm{N}=665 \\
\begin{array}{l}\text { Zoledronic Acid } \mathrm{n}=333 \\
\text { Placebo } \\
\mathrm{n}=332\end{array}\end{array}$ & \begin{tabular}{|l} 
Screening Failure \\
N= 646 \\
$\quad$ Protocol violation: 545 \\
Subject withdrew consent: 64 \\
Others: 37 \\
\end{tabular} \\
\hline $\begin{array}{l}\text { Full analysis set (FAS) } \\
\begin{array}{l}\mathrm{N}=661 \\
\text { Zoledronic Acid } \mathrm{n}=330 \\
\text { Placebo } \quad \mathrm{n}=331\end{array}\end{array}$ & $\begin{array}{l}\text { Discontinued } \\
\mathrm{N}=123 \\
\quad \text { Zoledronic Acid } \mathrm{n}=75\end{array}$ \\
\hline $\begin{array}{|ll|}\text { Completed } & \\
\mathrm{N}=542 & \\
\text { Zoledronic Acid } & \mathrm{n}=258 \\
\text { Placebo } & \mathrm{n}=284 \\
\end{array}$ & $\begin{array}{l}\text { Protocol violation: } 22 \\
\text { Adverse event: } 15 \\
\text { Others: } 5 \\
\text { Placebo } \quad \mathrm{n}=48 \\
\text { Withdrew consent: } 19 \\
\text { Protocol violation: } 19 \\
\text { Adverse event: } 6 \\
\text { Others: } 4 \\
\end{array}$ \\
\hline
\end{tabular}

Fig. 1 Patient flow. FAS full analysis set. A total of four subjects were excluded from FAS. Three subjects in the ZOL group violated the protocol, and one subject in the placebo group had no available efficacy data after the first dose of the study drug

$327)$ in the placebo group ( $p=0.0016)$. The RR of ZOL versus placebo was 0.34 (95\% CI: $0.17-0.69$ ), and the relative risk reduction (RRR) was $65.8 \%$ (the number needed to treat: 17) (Fig. 2a). The Kaplan-Meier estimates, the primary endpoint, were significantly lower in the ZOL group (3.3\%) than in the placebo group $(9.7 \%)(p=0.0029)$ (Fig. 2b). Two or more new morphometric vertebral fractures were observed in eight subjects in the placebo group but not observed in the ZOL group.

In female subjects, the incidence of new morphometric vertebral fracture was $2.9 \%$ (9/309 subjects) in the ZOL group and $8.8 \%(27 / 308)$ in the placebo group $(p=0.0019)$. The RR of ZOL versus placebo was 0.33 (95\% CI: 0.16-0.69), and the RRR was $66.8 \%$ (Fig. 2a). In male subjects, the incidence of new morphometric vertebral fracture was $4.8 \%$ (1/21 subjects) in the ZOL group and $10.5 \%(2 / 19)$ in the placebo group $(p=0.5962)$.

The cumulative incidence of any clinical fracture in the ZOL and placebo groups was 8.2 and $17.2 \%$ at 24 months, respectively ( $p=0.0014)$. The cumulative incidence of clinical vertebral fracture in the ZOL and placebo groups was 1.7 and $5.6 \%$ at 24 months, respectively ( $p=0.0130$ ) (Table 2). The cumulative incidence of non-vertebral fracture in the ZOL and placebo groups was 6.9 and $12.3 \%$ at 24 months, respectively ( $p=0.0292$ ) (Fig. 2c). The incidence of the osteoporotic fracture in the $\mathrm{ZOL}$ and placebo groups was 5.2 and $11.8 \%$ at 24 months, respectively $(p=0.0031)$. The number of non-vertebral osteoporotic fractures in the ZOL and placebo groups was 2 and 3 for hip fracture, 1 and 4 for tibia and fibula, 4 and 10 for rib, and 7 and 6 for upper extremity, respectively.

\section{BMD and bone turnover markers}

The mean percent change from baseline in the lumbar spine (L1-4) BMD at 6, 12, and 24 months was significantly higher in the ZOL group than that in the placebo group at each time point $(p<0.0001)$ (Fig. 3a). After 24 months, the percent increase was $8.11 \%$ in the ZOL group. The mean percent change from baseline in femoral neck BMD and total hip BMD at 6,12 , and 24 months was significantly higher in the ZOL group than in the placebo group at each time point $(p<0.001)$ (Fig. 3b, c). After 24 months, the percent increase in the femoral neck and total hip BMD was 3.63 and $3.30 \%$, respectively (Fig. 3b, c). The proportion of subjects with L1-4 BMD $T$ score $\geq-2.5$ was $37.2 \%$ at baseline and $54.2 \%$ at 24 months in the ZOL group.

In the ZOL group, serum CTx significantly decreased from 1 week after administration of both the first and second doses (Fig. 3d). In the ZOL group, serum BAP gradually decreased until 3 months after the first dose (Fig. 3e). Both markers in the ZOL group maintained lower levels for 24 months. No significant changes in these markers were seen in the placebo group.

\section{Safety}

AEs occurred at a rate of $94.6 \%$ in the ZOL group and $92.2 \%$ in the placebo group ( $p=0.2165)$ (Table 3 ). Drugrelated AEs occurred at a rate of $59.2 \%$ in the ZOL group and $12 \%$ in the placebo group; the incidence was significantly higher in the ZOL group $(p<0.0001)$. This difference was due to the occurrence of APRs - such as pyrexia (39.3 and $2.7 \%$ in ZOL and placebo group, respectively), arthralgia (10.8 and $0.3 \%$ ), myalgia ( 8.1 and $0 \%$ ), malaise (7.8 and $1.8 \%$ ), influenza-like illness (6.9 and $0 \%$ ), and headache (6.0 and $0.9 \%)$-in the ZOL group within 3 days of administration. Most of these were resolved within 3 days of onset. There were two deaths in the ZOL group and three deaths in the placebo group. In each case, the investigator ruled out a causal relationship with the study drug. Serious AEs occurred at a rate of $17.4 \%$ in the ZOL group and $13.3 \%$ in the placebo group. Of these serious AEs, a drug-related AE was observed in one subject in the ZOL group (pneumonia) and one subject in the placebo group (atrial fibrillation). Elongation of QT/QTc $>500 \mathrm{msec}$ was observed in one out of 47 subjects in the ZOL group, although this had also been observed in the subject at baseline. No tendency toward prolongation of QT/QTc was observed in either group. Osteonecrosis of the jaw and atypical femoral fracture were not observed in this study. 
Table 1 Baseline characteristics of the study subjects

\begin{tabular}{|c|c|c|}
\hline & Zoledronic acid $(N=330)$ & Placebo $(N=331)$ \\
\hline \multicolumn{3}{|l|}{ Sex } \\
\hline Male & $21(6.4 \%)$ & $19(5.7 \%)$ \\
\hline Female & $309(93.6 \%)$ & $312(94.3 \%)$ \\
\hline Age (years) & $74.0 \pm 5.4$ & $74.3 \pm 5.4$ \\
\hline Height (cm) & $149.79 \pm 6.57$ & $149.63 \pm 5.97$ \\
\hline Weight $(\mathrm{kg})$ & $52.35 \pm 7.53$ & $52.07 \pm 8.23$ \\
\hline Body mass index $\left(\mathrm{kg} / \mathrm{m}^{2}\right)$ & $23.36 \pm 3.22$ & $23.26 \pm 3.47$ \\
\hline \multicolumn{3}{|l|}{ Prior usage of bisphosphonates } \\
\hline Never used & $298(90.3 \%)$ & $303(91.5 \%)$ \\
\hline Used with sufficient washout & $32(9.7 \%)$ & $28(8.5 \%)$ \\
\hline \multicolumn{3}{|c|}{ Maximum grade of prevalent vertebral fractures at baseline } \\
\hline 0 & $29(8.8 \%)$ & $35(10.6 \%)$ \\
\hline 1 & $54(16.4 \%)$ & $53(16.0 \%)$ \\
\hline 2 & $136(41.2 \%)$ & $144(43.5 \%)$ \\
\hline 3 & $111(33.6 \%)$ & $99(29.9 \%)$ \\
\hline \multicolumn{3}{|c|}{ Number of prevalent vertebral fractures at baseline } \\
\hline 0 & $29(8.8 \%)$ & $35(10.6 \%)$ \\
\hline 1 & $167(50.6 \%)$ & $161(48.6 \%)$ \\
\hline 2 & $86(26.1 \%)$ & $84(25.4 \%)$ \\
\hline$\geq 3$ & $48(14.5 \%)$ & $51(15.4 \%)$ \\
\hline Lumbar spine $T$ score $(\mathrm{L} 1-\mathrm{L} 4)^{\mathrm{a}}$ & $-2.87 \pm 0.84$ & $-2.97 \pm 0.83$ \\
\hline$\leq-2.5$ & $93(62.4 \%)$ & $118(72.0 \%)$ \\
\hline$>-2.5-1.5$ & $53(35.6 \%)$ & $40(24.4 \%)$ \\
\hline$>-1.5$ & $3(2.0 \%)$ & $6(3.7 \%)$ \\
\hline Femoral neck $T$ score $^{\mathrm{b}}$ & $-2.95 \pm 0.87$ & $-2.94 \pm 0.85$ \\
\hline$\leq-2.5$ & $160(69.6 \%)$ & $167(71.7 \%)$ \\
\hline$>-2.5-1.5$ & $59(25.7 \%)$ & $56(24.0 \%)$ \\
\hline$>-1.5$ & $11(4.8 \%)$ & $10(4.3 \%)$ \\
\hline Total hip $T$ score $^{\mathrm{b}}$ & $-2.27 \pm 0.95$ & $-2.20 \pm 0.89$ \\
\hline$\leq-2.5$ & $98(42.6 \%)$ & $82(35.2 \%)$ \\
\hline$>-2.5-1.5$ & $83(36.1 \%)$ & $98(42.1 \%)$ \\
\hline$>-1.5$ & $49(21.3 \%)$ & $53(22.7 \%)$ \\
\hline Lumbar spine BMD $(\mathrm{L} 1-4)\left(\mathrm{g} / \mathrm{cm}^{2}\right)^{\mathrm{a}}$ & $0.66 \pm 0.09$ & $0.66 \pm 0.09$ \\
\hline Femoral neck BMD $\left(\mathrm{g} / \mathrm{cm}^{2}\right)^{\mathrm{b}}$ & $0.53 \pm 0.08$ & $0.53 \pm 0.08$ \\
\hline Total hip BMD $\left(\mathrm{g} / \mathrm{cm}^{2}\right)^{\mathrm{b}}$ & $0.65 \pm 0.10$ & $0.66 \pm 0.09$ \\
\hline 25-OH Vitamin D (ng/mL) & $26.17 \pm 6.54$ & $25.79 \pm 6.52$ \\
\hline
\end{tabular}

Plus-minus values are expressed as mean \pm standard deviation $B M D$ bone mineral density

${ }^{a}$ The analysis of BMD at the lumbar spine included 149 subjects in the zoledronic acid group and 164 in the placebo group

${ }^{\mathrm{b}}$ The analysis of BMD at the femoral neck and total hip included 230 subjects in the zoledronic acid group and 233 in the placebo group

\section{Discussion}

This study demonstrated that once-yearly administration of ZOL significantly reduced the risk of new morphometric vertebral fractures and increased BMD with a reduction in bone turnover in Japanese patients with primary osteoporosis. This study showed no apparent adverse events that had not been identified in previous clinical trials of ZOL. As the number of men included in the study was low $(6.1 \%)$, the data mainly represent the efficacy and safety of ZOL in postmenopausal women with osteoporosis. 
a

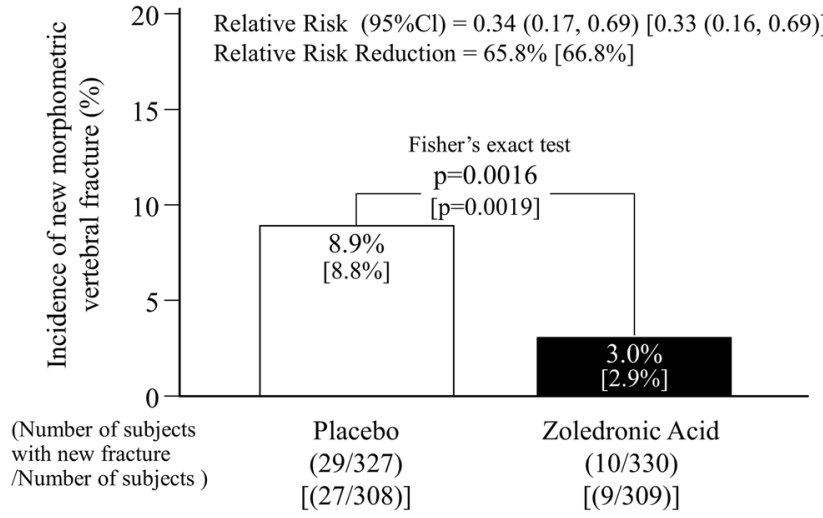

b

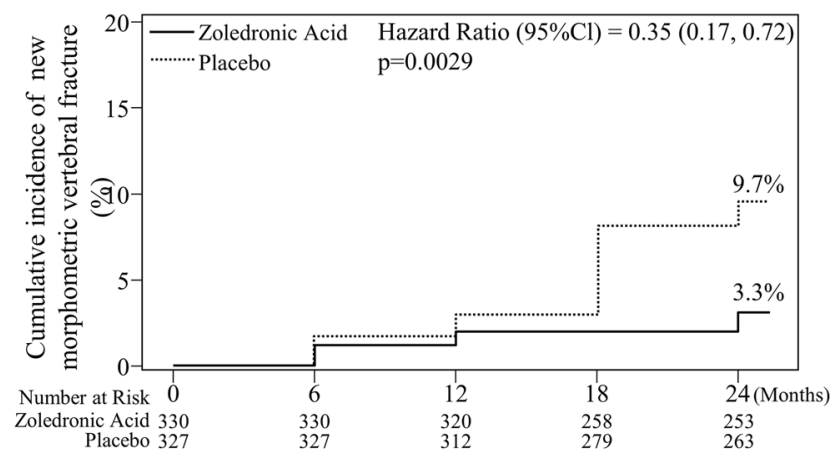

C

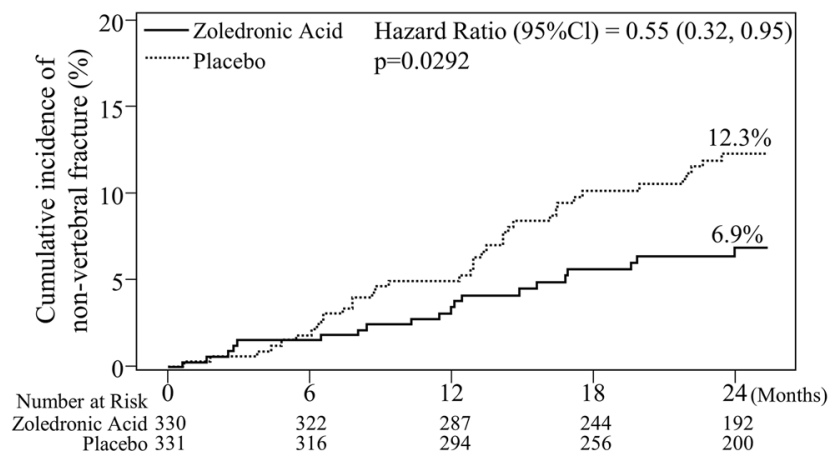

Fig. 2 Incidence of fractures during the 2-year study period. a Incidence of new morphometric vertebral fracture. Brackets indicate data for females only. Kaplan-Meier plots of incidence of $\mathbf{b}$ new morphometric vertebral fracture and $\mathbf{c}$ non-vertebral fracture. Statistical significance was assessed using log-rank tests, and $95 \%$ confidence intervals $(95 \%$ CI; lower limit, upper limit) were calculated using the Cox regression analysis

The efficacy of ZOL to reduce the risk of new morphometric vertebral fracture in Japanese patients with primary osteoporosis is similar to that seen in HORIZON-PFT. The proportion of subjects with prevalent vertebral fractures at baseline was approximately $90 \%$ in this study, whereas it was $60 \%$ in HORIZON-PFT. Subjects with severe (SQ3) prevalent vertebral fractures were included in this study, whereas they were excluded in HORIZON-PFT. The high incidence rate of vertebral fracture in this study is due to the increased fracture risks in the study subjects (e.g. prevalence of vertebral fractures and severe deformity) [15]. Mean BMD values were also lower in this study. Another possible explanation for the high occurrence of vertebral fractures in this study relates to the ethnicity of the subjects. It has been reported that the risk of vertebral fracture in Japanese postmenopausal women is higher than that in Caucasians [16]. In HORIZON-PFT, Asian subjects showed a higher incidence of vertebral fracture than other ethnic groups, although the efficacy of ZOL to reduce the risk of vertebral fracture did not differ among ethnic groups [17].

In this study, patients who were administered ZOL showed significant decreases in the incidence of any clinical fractures, clinical vertebral fractures, and non-vertebral fractures. These data are consistent with the results obtained in HORIZONPFT. To our knowledge, this is the first report showing the efficacy of a bisphosphonate to reduce the incidence of nonvertebral fractures in Japanese subjects. The incidence of osteoporotic fracture as defined by WHO was also significantly lower in the ZOL group than that in the placebo group. These data may imply that ZOL reduces the risk of fractures, including non-vertebral fractures, which increase the risk of subsequent fractures in patients with osteoporosis [18]. However, we did not stratify between fragility and non-fragility fractures in the collection of non-vertebral fracture data due to involving traumatic fractures, nor were these types of fractures set as the primary endpoint; therefore, we are not able to estimate the quantitative efficacy of ZOL in preventing non-vertebral fragility fractures in Japanese patients with osteoporosis.

The mean percent change from the baseline in the lumbar spine, total hip, and femoral neck BMD was significantly higher in the ZOL group than that in the placebo group at all assessment time points in this study. The values of percent increase in lumbar spine BMD were larger than those in HORIZON-PFT. A possible reason for the larger percent increases is due to the smaller baseline BMD values in this study. The absolute values of increased lumbar BMD from baseline seemed to be equivalent between the two studies. In this study, bone resorption marker (CTx) decreased rapidly after administration of ZOL followed by a decrease in bone formation marker (BAP). These markers maintained lower levels in the ZOL group than in the placebo group during the study. The changes over time in these bone turnover markers were similar to the findings in HORIZON-PFT. The potency of once-yearly administration of ZOL $5 \mathrm{mg}$ to reduce bone turnover and increase BMD in Japanese subjects seems to be similar to that seen in HORIZON-PFT.

Most of the AEs found to be higher in the ZOL group are those relating to APRs. In the ZOL group, pyrexia was reported in $39.3 \%$ of the subjects in this study, while it was reported in $16.1 \%$ of subjects in HORIZON-PFT [5]. Ethnic differences in the occurrence of APRs have been confirmed in HORIZON-PFT, with respective univariate odds ratios of 
Table 2 Effect of once-yearly treatment with zoledronic acid on the incidence of fractures at

24 months

\begin{tabular}{|c|c|c|c|c|c|c|c|}
\hline \multirow[t]{2}{*}{ Clinical fracture } & \multicolumn{3}{|c|}{ Zoledronic acid } & \multicolumn{3}{|c|}{ Placebo } & \multirow[t]{2}{*}{ Log-rank test HR $(95 \% \mathrm{CI})^{\mathrm{b}}$} \\
\hline & $n$ & $N$ & $(\%)^{\mathrm{a}}$ & $n$ & $N$ & $(\%)^{\mathrm{a}}$ & \\
\hline Any clinical fracture & 24 & 330 & 8.2 & 52 & 331 & 17.2 & $\begin{array}{l}P=0.0014 \\
0.46(0.29,0.75)\end{array}$ \\
\hline Clinical vertebral fracture & 5 & 330 & 1.7 & 17 & 331 & 5.6 & $\begin{array}{l}P=0.0130 \\
0.30(0.11,0.82)\end{array}$ \\
\hline Non-vertebral fracture & 20 & 330 & 6.9 & 37 & 331 & 12.3 & $\begin{array}{l}P=0.0292 \\
0.55(0.32,0.95)\end{array}$ \\
\hline
\end{tabular}

$H R$ hazard ratio and $95 \%$ CI $95 \%$ confidence interval

${ }^{a}$ Kaplan-Meier estimate

${ }^{\mathrm{b}}$ Calculated using Cox regression analysis. Data are expressed as $95 \%$ CIs (lower limit, upper limit)

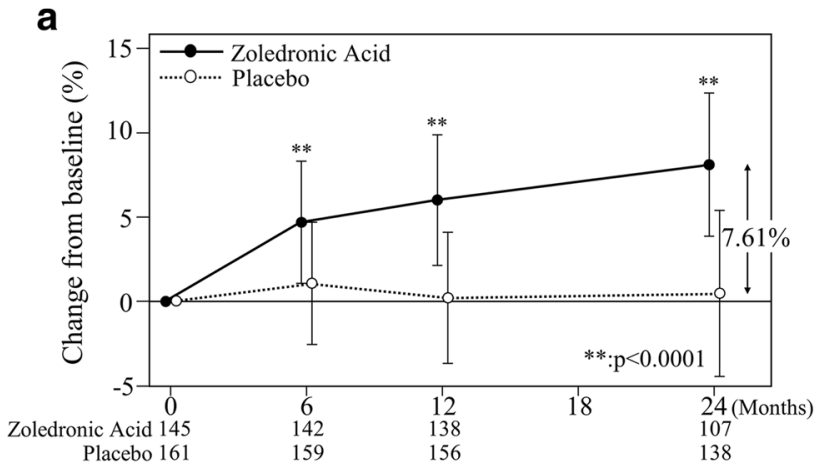

b

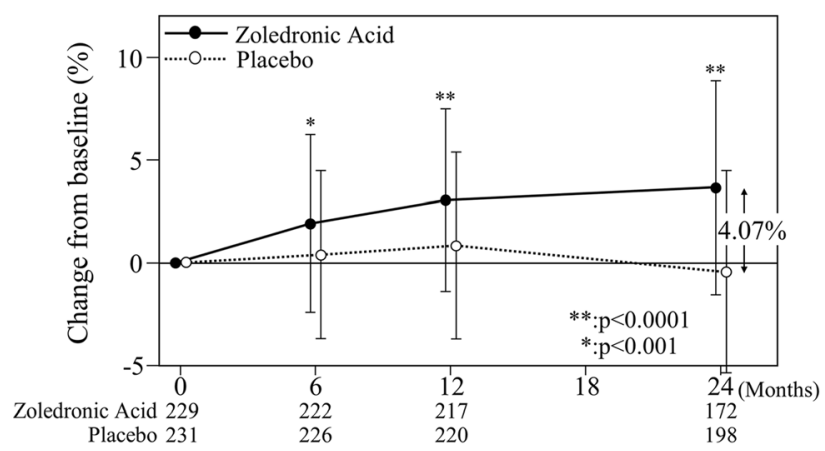

C

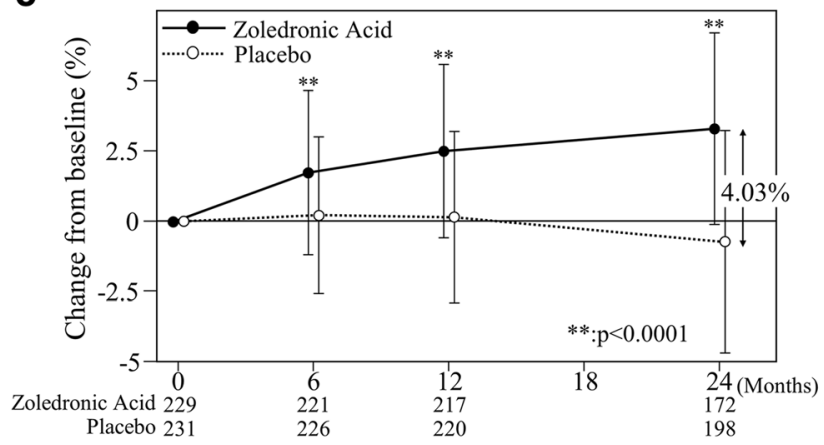

d

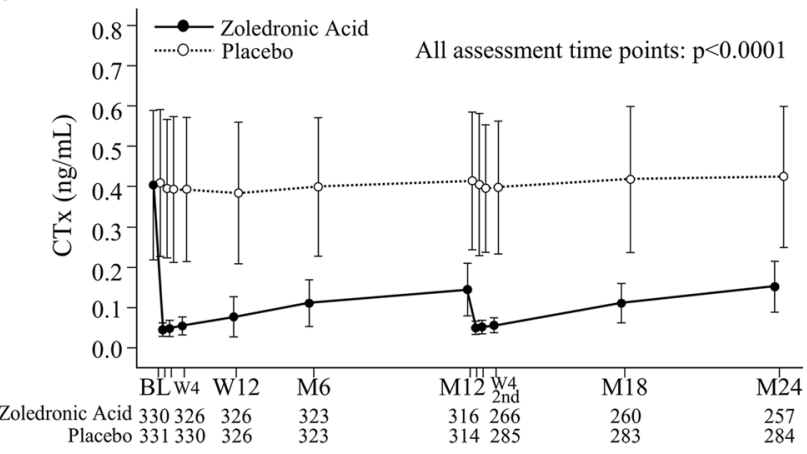

All assessment time points: $\mathrm{p}<0.01$

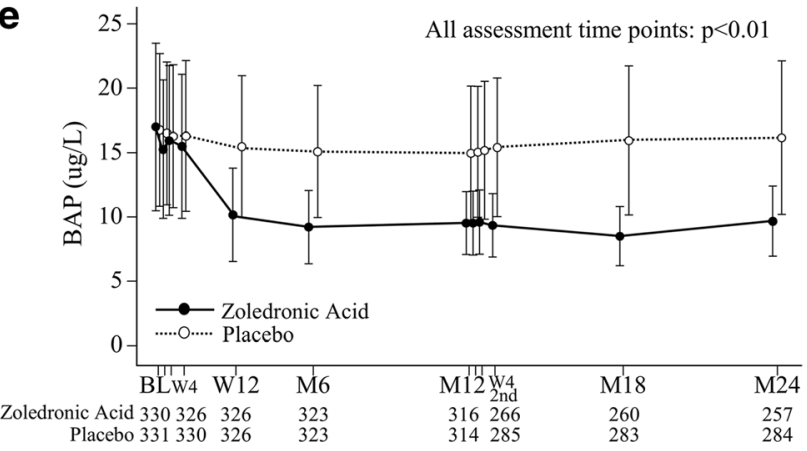

significance was assessed using the $t$ test. BMD bone mineral density, $C T x$ C-telopeptide, and $B A P$ bone alkaline phosphatase 
Table 3 Adverse events

\begin{tabular}{|c|c|c|}
\hline \multirow[t]{2}{*}{ Events } & \multicolumn{2}{|l|}{ All AEs } \\
\hline & Zoledronic acid $(N=333) n(\%)$ & Placebo $(N=332) n(\%)$ \\
\hline \multicolumn{3}{|l|}{ Overall incidence of AEs } \\
\hline Any AE & $315(94.6)$ & $306(92.2)$ \\
\hline Any serious $\mathrm{AE}$ & $58(17.4)$ & $44(13.3)$ \\
\hline Discontinuation of the study drug & $12(3.6)$ & $6(1.8)$ \\
\hline Death & $2(0.6)$ & $3(0.9)$ \\
\hline \multicolumn{3}{|l|}{$\mathrm{AE}$ (at least $5.0 \%$ for any group) } \\
\hline Pyrexia & $131(39.3)$ & $11(3.3)$ \\
\hline Nasopharyngitis & $116(34.8)$ & $90(27.1)$ \\
\hline Arthralgia & $54(16.2)$ & $24(7.2)$ \\
\hline Osteoarthritis & $44(13.2)$ & $39(11.7)$ \\
\hline Myalgia & $36(10.8)$ & $6(1.8)$ \\
\hline Eczema & $31(9.3)$ & $24(7.2)$ \\
\hline Constipation & $30(9.0)$ & $29(8.7)$ \\
\hline Malaise & $30(9.0)$ & $10(3.0)$ \\
\hline Fall & $29(8.7)$ & $29(8.7)$ \\
\hline Periarthritis & $29(8.7)$ & $21(6.3)$ \\
\hline Contusion & $28(8.4)$ & $43(13.0)$ \\
\hline Headache & $25(7.5)$ & $13(3.9)$ \\
\hline Blood calcium decreased & $24(7.2)$ & $2(0.6)$ \\
\hline Influenza-like illness & $23(6.9)$ & $0(0.0)$ \\
\hline Back pain & $21(6.3)$ & $18(5.4)$ \\
\hline Upper respiratory tract inflammation & $21(6.3)$ & $18(5.4)$ \\
\hline Protein urine present & $21(6.3)$ & $4(1.2)$ \\
\hline Dermatitis contact & $18(5.4)$ & $16(4.8)$ \\
\hline Spinal osteoarthritis & $17(5.1)$ & $14(4.2)$ \\
\hline
\end{tabular}

$A E$ adverse event

2.20 and 3.39 for non-Japanese Asians and Pacific Islanders after adjustment for the other variables [19]. The high occurrence of pyrexia in this study may reflect the ethnic differences in APRs to intravenous administration of a bisphosphonate. The APRs, including pyrexia, myalgia, and influenza-like illness, that occurred in this study mostly resolved within 3 days of onset as has been reported before [20]. In this study, if the subjects felt feverish after infusion, they were asked to take their temperature four times a day. A study focusing on the rate of pyrexia after infusion with ZOL showed that $60 \%$ of the subjects had a significant increase in oral temperature over a 3-day period after infusion [20]. Therefore, it is likely that the frequency and duration of recording body temperature affect the incidence of pyrexia AEs after infusion with ZOL.

This study did have some limitations, including the small sample size, the short study period, and the strict patient enrollment criteria. Furthermore, a few male patients with osteoporosis were enrolled in this study. However, this study demonstrated that once-yearly administration of ZOL significantly reduced the risk of new morphometric vertebral fractures in postmenopausal women with primary osteoporosis. Although the duration of this study and the duration of HORIZON-PFT were only 24 and 36 months, respectively, osteonecrosis of the jaw was not observed in this study and no difference in the incidence was observed between the ZOL and placebo groups in HORIZONPFT (one in each group). The study was also underpowered to test the efficacy of zoledronic acid on the prevention of hip fracture. Based on the results of a national nutrition survey in Japan, the dietary calcium intake of Japanese patients with primary osteoporosis was approximately $300 \mathrm{mg}$ lower than the required daily intake according to Japanese guidelines [21]. The required daily intake of dietary calcium and vitamin $\mathrm{D}$ is $800 \mathrm{mg}$ and 400-800 IU, respectively. Therefore, the doses of calcium (610 mg) and vitamin D (400 IU) in this study were considered enough to supplement the daily intake.

In conclusion, this study demonstrated the efficacy and safety of once-yearly administration of ZOL $5 \mathrm{mg}$ in Japanese patients (mainly women) with primary osteoporosis. Both the efficacy and safety of once-yearly infusion of ZOL $5 \mathrm{mg}$ in Japanese subjects seem equivalent to those seen in the global HORIZON-PFT study. These results suggest that ZOL may be beneficial for the treatment of primary osteoporosis in Japan. 
Acknowledgments The study was sponsored and funded by the Asahi Kasei Pharma Corporation, Tokyo, Japan. The sponsor had responsibility for quality control. The corresponding author had full access to all of the data in the study and had responsibility for the decision to submit for publication. We thank the investigators and clinical sites in Japan that participated in this study.

The clinical trial registration number identifier (www.clinicaltrials. gov) is NCT01522521.

The study was jointly designed by the authors and the sponsor, Asahi Kasei Pharma Corporation.

The authors discussed the interpretation of the data and the conclusions of the manuscript with the sponsor. Data analyses for publication were the responsibilities of the sponsor. This manuscript was reviewed by Novartis Pharma AG prior to submission for publication.

Compliance with ethical standards This study was conducted in compliance with the World Medical Association Declaration of HelsinkiEthical Principles for Medical Research Involving Human Subjects and Good Clinical Practice. The protocol was reviewed by the institutional review board at each study site. Written informed consent was obtained from all subjects before enrollment in the study.

Conflicts of interest TN has received consulting fees from Asahi Kasei Pharma, Amgen, Chugai Pharmaceutical, Daiichi-Sankyo, Eli Lilly Japan, MSD, Taisho Toyama Pharmaceutical, and Teijin Pharma. MF has received consulting fees from Asahi Kasei Pharma and lecture fees from Daiichi-Sankyo and MSD. TN has received consulting fees from Asahi Kasei Pharma, Chugai Pharmaceutical, Daiichi-Sankyo, and Teijin Pharma. HK has received consulting fees from Ajinomoto and Asahi Kasei Pharma. MI has received consulting fees from Asahi Kasei Pharma, Astellas Pharma, Chugai Pharmaceutical, Daiichi-Sankyo, MSD, and Ono Pharmaceutical. HH has received research grants, consulting fees, and/or lecture fees from Asahi Kasei Pharma, Astellas Pharma, Chugai Pharmaceutical, Daiichi-Sankyo, Eisai, Eli Lilly Japan, Mitsubishi Tanabe Pharma, MSD, Ono Pharmaceutical, Pfizer, Taisho Toyama Pharmaceutical, Takeda Pharmaceutical, and Teijin Pharma. TS has received research grants from Asahi Kasei Pharma, Astellas Pharma, Daiichi-Sankyo, Taisho Toyama Pharmaceutical, Takeda Pharmaceutical, Pfizer and Teijin Pharma, and consulting fees from Takeda Pharmaceutical. AT has received consulting fees and lecture fees from Asahi Kasei Pharma, Daiichi-Sankyo, MSD, Ono Pharmaceutical, Takeda Pharmaceutical, and Teijin Pharma. ST, MO, and YO are employees of Asahi Kasei Pharma. MS has received consulting fees from Asahi Kasei Pharma, MSD, and Teijin Pharma and received lecture fees from Astellas Pharma, Chugai Pharmaceutical, Daiichi-Sankyo, Eisai, Eli Lilly Japan, Ono Pharmaceutical, and Pfizer.

Open Access This article is distributed under the terms of the Creative Commons Attribution-NonCommercial 4.0 International License (http:// creativecommons.org/licenses/by-nc/4.0/), which permits any noncommercial use, distribution, and reproduction in any medium, provided you give appropriate credit to the original author(s) and the source, provide a link to the Creative Commons license, and indicate if changes were made.

\section{References}

1. Russell RG, Xia Z, Dunford JE, Oppermann U, Kwaasi A, Hulley PA, Kavanagh KL, Triffitt JT, Lundy MW, Phipps RJ, Barnett BL, Coxon FP, Rogers MJ, Watts NB, Ebetino FH (2007)
Bisphosphonates: an update on mechanisms of action and how these relate to clinical efficacy. Ann N Y Acad Sci 1117:209-257

2. Reid IR, Brown JP, Burckhardt P, Horowitz Z, Richardson P, Trechsel U, Widmer A, Devogelaer JP, Kaufman JM, Jaeger P, Body JJ, Brandi ML, Broell J, Di Micco R, Genazzani AR, Felsenberg D, Happ J, Hooper MJ, Ittner J, Leb G, Mallmin H, Murray T, Ortolani S, Rubinacci A, Saaf M, Samsioe G, Verbruggen L, Meunier PJ (2002) Intravenous zoledronic acid in postmenopausal women with low bone mineral density. New Engl J Med 346:653-661

3. Devogelaer JP, Brown JP, Burckhardt P, Meunier PJ, Goemaere S, Lippuner K, Body JJ, Samsioe G, Felsenberg D, Fashola T, Sanna L, Ortmann CE, Trechsel U, Krasnow J, Eriksen EF, Garnero P (2007) Zoledronic acid efficacy and safety over five years in postmenopausal osteoporosis. Osteoporosis Int 18:1211-1218

4. McClung M, Recker R, Miller P, Fiske D, Minkoff J, Kriegman A, Zhou W, Adera M, Davis J (2007) Intravenous zoledronic acid $5 \mathrm{mg}$ in the treatment of postmenopausal women with low bone density previously treated with alendronate. Bone 41:122-128

5. Black DM, Delmas PD, Eastell R, Reid IR, Boonen S, Cauley JA, Cosman F, Lakatos P, Leung PC, Man Z, Mautalen C, Mesenbrink P, Hu H, Caminis J, Tong K, Rosario-Jansen T, Krasnow J, Hue TF, Sellmeyer D, Eriksen EF, Cummings SR (2007) Once-yearly zoledronic acid for treatment of postmenopausal osteoporosis. N Engl J Med 356:1809-1822

6. Reid DM, Devogelaer JP, Saag K, Roux C, Lau CS, Reginster JY, Papanastasiou P, Ferreira A, Hartl F, Fashola T, Mesenbrink P, Sambrook PN (2009) Zoledronic acid and risedronate in the prevention and treatment of glucocorticoid-induced osteoporosis (HORIZON): a multicentre, double-blind, double-dummy, randomised controlled trial. Lancet 373:1253-1263

7. Boonen S, Reginster JY, Kaufman JM, Lippuner K, Zanchetta J, Langdahl B, Rizzoli R, Lipschitz S, Dimai HP, Witvrouw R, Eriksen E, Brixen K, Russo L, Claessens F, Papanastasiou P, Antunez O, Su G, Bucci-Rechtweg C, Hruska J, Incera E, Vanderschueren D, Orwoll E (2012) Fracture risk and zoledronic acid therapy in men with osteoporosis. N Engl J Med 367:1714 1723

8. Lyles KW, Colón-Emeric CS, Magaziner JS, Adachi JD, Pieper CF, Mautalen C, Hyldstrup L, Recknor C, Nordsletten L, Moore KA, Lavecchia C, Zhang J, Mesenbrink P, Hodgson PK, Abrams K, Orloff JJ, Horowitz Z, Eriksen EF, Boonen S (2007) Zoledronic acid and clinical fractures and mortality after hip fracture. N Engl J Med 357:1799-1809

9. Orimo H, Hayashi Y, Fukunaga M, Sone T, Fujiwara S, Shiraki M, Kushida K, Miyamoto S, Souen S, Nishimura J, Ohashi Y, Hosoi T, Gorai I, Tanaka H, Ikai T, Kishimoto H (2001) Committee to study diagnostic criteria for osteoporosis of the Japanese Society for Bone and Mineral Research. Diagnostic criteria for primary osteoporosis (2000 revision). J Bone Miner Metab 18:76-82

10. Kanis JA, on behalf of the World Health Organization Scientific Group (2007) Assessment of osteoporosis at the primary healthcare level. WHO Collaborating Centre for Metabolic Bone Diseases, University of Sheffield

11. Genant HK, Wu CY, Kuijk CV, Nevitt MC (1993) Vertebral fracture assessment using a semiquantitative technique. J Bone Miner Res 8: $1137-1148$

12. Wu CY, Li J, Jergas M, Genant HK (1995) Comparison of semiquantitative and quantitative techniques for the assessment of prevalent and incident vertebral fractures. Osteoporos Int 5:354-370

13. Matsumoto T, Hagino H, Shiraki M, Fukunaga M, Nakano T, Takaoka K, Morii H, Ohashi Y, Nakamura T (2009) Effect of daily oral minodronate on vertebral fractures in Japanese postmenopausal women with established osteoporosis: a randomized placebocontrolled double-blind study. Osteoporosis Int 20:1429-1437 
14. Nakamura T, Sugimoto T, Nakano T, Kishimoto H, Ito M, Fukunaga M, Hagino H, Sone T, Yoshikawa H, Nishizawa Y, Fujita T, Shiraki M (2012) Randomized Teriparatide [human parathyroid hormone (PTH) 1-34] once-weekly efficacy research (TOWER) trial for examining the reduction in new vertebral fractures in subjects with primary osteoporosis and high fracture risk. $\mathrm{J}$ Clin Endocrinol Metab 97:3097-3106

15. Lindsay R, Silverman SL, Cooper C, Hanley DA, Barton I, Broy SB, Licata A, Benhamou L, Geusens P, Flowers K, Stracke H, Seeman E (2001) Risk of new vertebral fracture in the year following a fracture. JAMA 285:320-323

16. Ross PD, Fujiwara S, Huang C, Davis JW, Epstein RS, Wasnich RD, Kodama K, Melton LJ 3rd (1995) Vertebral fracture prevalence in women in Hiroshima compared to Caucasians or Japanese in the US. Int J Epidemiol 24:1171-1177

17. Hwang JS, Chin LS, Chen JF, Yang TS, Chen PQ, Tsai KS, Leung PC (2011) The effects of intravenous zoledronic acid in Chinese women with postmenopausal osteoporosis. J Bone Miner Metab $29: 328-333$
18. Gehlbach S, Saag KG, Adachi JD, Hooven FH, Flahive J, Boonen S, Chapurlat RD, Compston JE, Cooper C, Díez-Perez A, Greenspan SL, LaCroix AZ, Netelenbos JC, Pfeilschifter J, Rossini M, Roux C, Sambrook PN, Silverman S, Siris ES, Watts NB, Lindsay R (2012) Previous fractures at multiple sites increase the risk for subsequent fractures: the global longitudinal study of osteoporosis in women. J Bone Miner Res 27:645-653

19. Reid IR, Gamble GD, Mesenbrink P, Laketos P, Black DM (2010) Characterization of and risk factors for the acute-phase response after zoledronic acid. J Clin Endocrinol Metab 95:4380-4387

20. Wark JD, Bensen W, Recknor C, Ryabitseva O, Chiodo J 3rd, Mesenbrink P, de Villiers TJ (2012) Treatment with acetaminophen/paracetamol or ibuprofen alleviates post-dose symptoms related to intravenous infusion with zoledronic acid $5 \mathrm{mg}$. Osteoporosis Int 23:503-512

21. Orimo H, Nakamura T, Hosoi T, Iki M, Uenishi K, Endo N, Ohta H, Shiraki M, Sugimoto T, Suzuki T, Soen S, Nishizawa Y, Hagino H, Fukunaga M, Fujiwara S (2012) Japanese 2011 guidelines for prevention and treatment of osteoporosis - executive summary. Arch Osteoporos 7:3-20 